\title{
NOTAS
}

\section{QUINCE AÑOS DE FILOLOGÍA ESPAÑOLA EN EL CONTEXTO EUROPEO (1912-1927). \\ A propósito de la publicación del libro Leo Spitzers Briefe \\ an Hugo Schuchardt ${ }^{1}$}

\author{
$M^{\mathrm{a}}$ TERESA ECHENIQUE ELIZONDO \\ Universidad de Valencia
}

El marco filológico en el que se desenvuelve la correspondencia dirigida por Leo Spitzer a Hugo Schuchardt entre los años 1912 y 1927 tiene en España como trasfondo la reactivación filológica impulsada por Ramón Menéndez Pidal. La Gramática histórica y la Dialectología contaban ya por entonces con sus pilares básicos, pues Menéndez Pidal había publicado el Manual de gramática histórica española ${ }^{2}$ en 1904 y El dialecto leonés en 1906, al tiempo que consolidaba la edición de textos con fundamentos sólidos: además del Poema del Cid en 1899, la Disputa del alma y el cuerpo y el Auto de los Reyes Magos, ambas obras en 1900, y la Razón de Amor en 1905, entre otros, en 1906 había publicado la Estoria de España de Alfonso X con el título Primera Crónica General de España, que mandó componer Alfonso el Sabio y se continuaba bajo Sancho IV en 1289, y entre 1908 y 1911 salieron los tres monumentales volúmenes del Cantar de Mio Cid. Texto, gramática y vocabulario.

La aparición del decreto de constitución del Centro de Estudios Históricos como uno de los primeros organismos dependientes de la Junta para Ampliación de Estudios, creada en 1907, tuvo lugar en 1910 y se convirtió en el germen de la escuela española de lingüística gracias a la actividad desarrollada en los años

1 Editado y dirigido por Bernhard Hurch, con la colaboración de Niklas Bender y Annemarie Müllner, Berlin/New York, Walter de Gruyter, 2006.

2 En rigor, el título de la primera edición fue Manual elemental de gramática histórica española, que desde la 4a edición de 1918 (corregida y aumentada) pasó a titularse Manual de gramática histórica española (V. Diego Catalán, Lingüística íbero-románica. Crítica retrospectiva, Madrid, Gredos, 1974, pág. 24). 
posteriores; vinculado a esta circunstancia, entre los años de la correspondencia que nos ocupa queda incluido el de 1914, comienzo de la Revista de Filología Española, que, además de la publicación periódica, dio lugar a adaptaciones de obras importantes de la lingüística europea con el objeto de contribuir a la formación de nuevos filólogos: la Introducción a la lingüística romance de MeyerLübke, con notas y adiciones de Américo Castro ${ }^{3}$, fue elegida en 1914 para inaugurar la serie. Hacia 1918 el propio Castro alababa en la RFE a Hugo Schuchardt por sus duras críticas a las doctrinas y métodos neogramáticos ${ }^{4}$. En 1923 se informaba, también en la $R F E$, sobre la realización de los trabajos preparatorios del ALPI. Por otro lado, Orígenes del español (1926) era positivamente valorada por Spitzer tres años después de su aparición ${ }^{5}$, época en que José Francisco Pastor, en calidad de becario del Centro de Estudios Históricos, traducía a Vossler al español. Ambos, Spitzer y Vossler, fueron profesores visitantes del Centro de Estudios Históricos (Spitzer en 1926, Vossler en 1929). La conjunción de todos estos factores favoreció el hecho de que, en el contexto europeo, los años veinte se convirtieran en la década correspondiente a la de estabilización institucional del hispanismo en las universidades alemanas ${ }^{6}$.

El trasvase e influjo entre los miembros de la escuela de Madrid y el hispanismo germánico, pues, se producía en forma directa en ambas direcciones; no en vano Dámaso había estado como lector en Berlín en 1922, y en 1927 se producía la rehabilitación de Góngora, con gran eco en el hispanismo internacional en general y en el centroeuropeo en particular. Añadamos a esta circunstancia otra que, contemplada desde la distancia, confiere valor histórico a la fecha en que termina la correspondencia dirigida por Leo Spitzer al maestro Schuchardt; en el año de la muerte de éste, justamente en 1927, es cuando Rafael Lapesa, a propuesta de Américo Castro, entró en el Centro de Estudios de Históricos para trabajar bajo la dirección de Menéndez Pidal.

Todas estas circunstancias explican la trascendencia y significación que para la Filología hispánica tiene en el momento presente la publicación del libro Leo Spitzers Briefe an Hugo Schuchardt a cargo de Bernhard Hurch, Director del Instituto de Lingüística de la Universidad de Graz, donde se custodia el legado de Hugo Schuchardt ${ }^{7}$, con la colaboración de Niklas Bender y Annemarie Müllner, convenientemente estructurado y ejemplarmente impreso.

\footnotetext{
3 Basada en la segunda edición alemana de 1909, muy enriquecida después en su tercera edición española de 1926.

4 En el artículo «Hugo Schuchardt» publicado en la RFE de ese año.

${ }^{5}$ En Meisterwerke der romanischen Sprachwissenschaft, Munich, I, 1929, págs. 352-353.

${ }^{6}$ Véase Dietrich Briesemeister, «Karl Vossler (1872-1949)», Boletín de la Asociación Internacional de Hispanistas, 12/5, 2006, pág. 31.

7 Se puede acceder a la actividad desarrollada en los últimos años en: http://schuchardt.unigraz.at. Las cartas originales de la correspondencia de Leo Spitzer a H. Schuchardt se guardan en
} 
El período cronológico que la correspondencia comprende es anterior al exilio al que Spitzer se vio abocado por las presiones derivadas de la creciente amenaza del nacionalsocialismo ${ }^{8}$, al igual que sucedió con otros filólogos como Erich Auerbach, Helmut Hatzfeld, Ernst Pulgram, Henry y Renée Kahane, o Yakov Malkiel, todos los cuales tuvieron mejor fortuna que la eminente romanista Elise Richter, copiosamente citada en el índice de personas que hay al final del libro que reseñamos, si bien autora de trabajos que han tenido menor repercusión entre nosotros; las menciones a su persona y obra en estos años anteriores a su trágico final en Theresienstadt en 1943 tienen un carácter espontáneo, ingenuo a veces, que dibuja la falta de anticipación de indicios anunciadores de los hechos que se avecinaban.

Así que la correspondencia de este joven Leo Spitzer (nacido en Viena en 1887) al consagrado romanista Hugo Schuchardt (hoy considerado austríaco por su fuerte arraigo en Graz, pero nacido en la ciudad alemana de Gotha en 1842) termina en 1927, año de su muerte. Sus nombres habían quedado inseparablemente unidos en 1922, cuando Spitzer recopiló los trabajos del ya anciano maestro y, acompañados de la lista completa de los publicados hasta entonces, fueron editados en su 80 cumpleaños como Hugo Schuchardt-Brevier. Ein Vademecum der allgemeinen Sprachwissenschaft ${ }^{9}$. A su muerte, Spitzer completó la lista de trabajos schuchardtianos posteriores; con carácter póstumo, y juntamente con un artículo dedicado a cuestiones de la lengua vasca y otro sobre el georgiano, se incluye precisamente una carta escrita a Leo Spitzer. De esta segunda edición del Hugo Schuchardt-Brevier ${ }^{10}$, así como de la obra Hugo Schuchardt escrita por Elise Richter ${ }^{11}$ y la de Hugo Schuchardt zana de Gerhard Bähr ${ }^{12}$, hizo una breve recensión con-

el Archivo de Hugo Schuchardt en la sección de manuscritos de la Biblioteca de la Universidad de Graz: están catalogadas con el número 10.763 al 11.215 (no olvidemos que la correspondencia dirigida a Schuchardt inventariada en la Universidad de Graz asciende a la cifra de casi 13.000 cartas); no se conservan, en cambio, la mayoría de las cartas escritas por Schuchardt a Spitzer, sino tan sólo algunas, que también se transcriben en el libro.

8 Se trasladó a Estambul en 1933 y a Baltimore en 1936, donde pasó a ser emérito en 1956. Rechazó una llamada de Colonia en 1946. En Hans Helmut Christmann y Frank-Rutger Hausmann (con la colaboración de Manfred Briegel), eds., Deutsche und österreichische Romanisten als Verfolgte der Nationalsozialismus, Tübingen, Stauffenburg, 1989, págs. 79-84, Willi Jung transcribe y analiza en el contexto apropiado la carta de 5 de mayo de 1946 escrita en Baltimore (Maryland) en la que Spitzer declina elegantemente la llamada; aún tuvo tiempo de regresar a Heidelberg como Profesor invitado en el semestre de verano de 1958, antes de su muerte en 1960.

9 Halle, Saale.

10 Tübingen, Max Niemeyer.

11 Publicada como Extrait del Archiv für das Studium der neueren Sprachen und Literaturen, 1928, págs. 224-258.

12 Aparecida en Pamplona en 1929 y «écrite en excellent basque guipuzcoan», como señala Georges Lacombe. En el volumen de la RIEV había hecho el propio Lacombe la reseña de la $1^{\mathrm{a}}$ edición del Hugo Schuchardt Brevier. 
junta Georges Lacombe en la Revista Internacional de Estudios Vascos ${ }^{13}$; el azar ha querido que en ese mismo número de la RIEV Spitzer escribiera un artículo sobre «Hugo Schuchardt als Briefschreiber» ${ }^{14}$, lo que permite hacerse una idea de la Filología sin fronteras que caracterizaba al Hispanismo del primer tercio del siglo XX.

Filólogo en sentido clásico, su formación conjunta en lengua y literatura es lo que allanó a Leo Spitzer el camino de su relación con Schuchardt, romanista no menos clásico, si bien volcado en los estudios lingüísticos y en la investigación sobre las lenguas sin atender a sus literaturas ${ }^{15}$. Es también un momento histórico en que la Filología hispánica se considera una parte de la Filología románica ${ }^{16}$; la amplia formación romanística (que llevaba aparejado en países germánicos, entonces al igual que hoy, el envidiable correcto conocimiento de las lenguas románicas en su conjunto, del que siempre hemos carecido en España) hacía posible la comunicación y correspondencia profesional entre filólogos de obra tan diversa como Hugo Schuchardt y Leo Spitzer.

El editor del libro, Bernhard Hurch, subraya en la página XIII del prólogo la capacidad de ambos para mantener una fluida, grata y sorprendentemente fecunda comunicación, no a pesar de, sino gracias a la variedad de intereses que ambos profesaban en la investigación, lo que le sirve como punto de arranque para una detallada exposición de la relación habida entre el ya venerable Schuchardt y el joven Spitzer, así como de la dimensión política de la figura de este último y de la estela de sus trabajos en el mundo de la Lingüística, en general, y de la Filología románica en particular.

Aunque Leo Spitzer no llegó a alcanzar el prestigio de Karl Vossler ni su obra tuvo tan masiva divulgación como la de su precursor en el ámbito peninsular (como ha recordado Dietrich Briesemeister ${ }^{17}$ ), su impronta no debe ser, ni mucho menos, desdeñada, de la misma manera que resulta inadecuado considerarle discípulo suyo. El afán por destacar lo que hay de individual y estético en

13 Tomo 21 (1930) de la $R I E V$, pág. 280. Lacombe había publicado la necrología de Schuchardt en la RIEV de 1927 (t. 18); en ese mismo número de la RIEV escribe Spitzer un breve trabajo: «Span. Ostugo = bask. *ostugo?» (págs. 634-635), en el que, según Corominas y Pascual (s. v. ostugo), Spitzer («en un artículo que no he podido consultar directamente») encuentra la verdadera etimología de esta voz.

14 Págs. 591-617.

15 La Tesis doctoral de Spitzer, bajo la dirección de Meyer-Lübke, es producto de la Viena de principios del siglo XX. No está de más señalar que tanto Leo Spitzer como Elise Richter tuvieron gran relación académica y profesaron verdadera admiración por Hugo Schuchardt, sin haber sido discípulos directos suyos; ambos lo eran de Meyer-Lübke, como oportunamente recuerda Bernhard Hurch en el prólogo del libro.

16 Véase J. Lüdtke (en Günther Haensch y Alfonso Muñoz Cosme, coords., Las aportaciones del hispanismo alemán y su recepción en España, Madrid, Instituto Cervantes, 1996, págs. 21-32).

17 Véase art. cit., pág. 31. 
la creación literaria tendría después amplia repercusión en los trabajos futuros de los dos Alonso ${ }^{18}$, hasta el punto de que no es raro encontrar unidos sus nombres en tratados de teoría literaria. Así, refiriéndose al valor crítico que la estilística aportó a consideraciones teóricas de más alto vuelo, afirma García Berrio: «El mismo Dámaso, Amado Alonso y Leo Spitzer dentro de nuestra tradición más propia jalonaron incomparablemente este itinerario de la crítica» ${ }^{19}$, para concluir con gravedad: «vuelve a ser muy urgente y extremadamente necesario para el equilibrado cuerpo metodológico del pensamiento literario, recordar la práctica estilística de los Alonso y Leo Spitzer y componer al fin un verdadero tratado de estilo literario del español...» ${ }^{20}$, afirmando aún a continuación que, en el pensamiento de Spitzer y los dos Alonso, hay «momentos de culminación teórica difícilmente igualables» ${ }^{21}$.

En sus cartas Spitzer pedía consejos al romanista y vascólogo Schuchardt en materia de lengua vasca y su léxico, claro está que relacionando siempre las formas vascas con las románicas, lo que resulta especialmente valioso. Es la época en que, como romanista, Spitzer se interesa de manera más inmediata por problemas del francés y del italiano, aunque las referencias a Cervantes están presentes desde los comienzos. Seguramente hay que ver en ello un indicio de la literatura leída y utilizada en clase, de acuerdo con la práctica de la mejor Romanística europea, al tiempo que explica las dudas y la curiosidad que le suscitan una palabra peculiar, como sucede con endilgar (pág. 153), las varias ocasiones en las que se ocupa del chau chau como reproducción del reclamo de la codorniz (para lo que cita a Pardo Bazán en la misma página y en la siguiente), o fadragas (voz presente en J. Ruiz, como apostilla), baldragas, faltaraka (pág.155), sobre cuyas conexiones con otras voces confiesa haber escrito lacónicamente, así como el mostrico en Pereda (pág.155) y su vinculación con mostrenco, o la filiación entre rebaño, rebañadura, rebanada y *REPANIARE, o escoznete, escueznar, cozneo con CUTINA + *COCIA: esta preocupación etimo-

18 Amado reconoció su deuda con los estudios estilísticos y cultivó tanto la «estilística de la lengua» como la «estilística del habla», ya en Buenos Aires: allí, entre otras cosas, puso en marcha en 1931 la «Colección de Estudios estilísticos», cuyo primer volumen, titulado Introducción a la estilística romance, recogía trabajos de Karl Vossler y Leo Spitzer, así como una reseña bibliográfica de Hatzfeld sobre «La investigación estilística en las literaturas románicas». El volumen de la misma colección de 1936, El impresionismo en el lenguaje, incluía un artículo de Elise Richter titulado «Impresionismo, expresionismo y gramática» (págs. 47-120) al lado de otros de Bally, Raimundo Lida o el propio Amado. Por otro lado, cuando años más tarde Dámaso publique Poesía española. Ensayo de métodos y límites estilísticos ya en 1950, Spitzer le dedicará su atención en Romanische Forschungen, 64, 1952, págs. 213-240.

19 Antonio García Berrio, Teoría de la Literatura. La construcción del significado poético, Madrid, Cátedra, $1994^{2}$, pág. 488.

20 Ibídem, pág. 488.

21 Ibídem, pág. 489. 
logista debía tener el mismo origen y ofrece ejemplos de gran erudición, como cuando diserta sobre la voz desmazalado en Cervantes, que le permite relacionar voces románicas con otras germánicas e incluso eslavas (págs. 24-25, 26, 28). De especial interés resulta la carta de 1 de agosto de 1921 (pág. 210), en la que juega con diversas etimologías, al tiempo que menciona, de pasada, el envío de una contribución suya a la $R F E$.

En 1914, Spitzer había hecho su aparición en el escenario catalán con sus «Syntaktische Noticien zum Catalanischen» ${ }^{22}$. En su correspondencia con Schuchardt hay referencias al catalán desde 1918, en su mirada de conjunto a las lenguas iberorrománicas: Spitzer ha manejado diccionarios catalanes (pág. 99), cita el Bolletí del Diccionari de la llengua catalana editado por Antoni Maria Alcover en Mallorca (pág. 101), el Butlletí de dialectología catalana (pág. 165), del que puntualiza que se publica desde 1913 en Barcelona; demuestra, así mismo, gran destreza en las referencias al ámbito portugués: cita a Carolina Michaelis de Vasconcellos ${ }^{23}$ desde 1912 (pág. 4) y numerosas revistas y publicaciones de ese ámbito. En 1919 ha consultado el Diccionario de voces aragonesas de Borao (pág. 105), en 1919 (pág. 107) discute simultáneamente voces vascas del Lexicón de Emiliano de Arriaga, otras aragonesas tras haber consultado a Borao y a Saroïhandy (lo hará también luego en pág. 299). Toda el área hispánica, en definitiva, sin dejar de prestar atención al elemento latino inserto en albanés, al italiano o al francés, como corresponde a un romanista integral.

La relación epistolar con Schuchardt no se limitaba a la mera consulta en la distancia, sino que iba acompañada de verdadera amistad en obras y hechos por ambas partes. Si en 1920 Spitzer ofrece a Schuchardt la RFE de los años 191620, con calurosa recomendación de trabajos de Menéndez Pidal y Castro (pág. 162), en agosto de 1920 (pág. 166), Spitzer da las gracias a Schuchardt por el ejemplar de la $R I E V$ recibido en préstamo, que dice devolverle unos días después (pág. 169).

En 1921 (pág. 185) aparece citado Menéndez Pidal con motivo de su Homenaje, a quien elogia tras su encuentro en 1926 (pág. 395), asegurando no haberle encontrado tan seco como se lo habían descrito, sino amable y con dotes para las relaciones personales. Más vehemente aún es su descripción de Américo Castro en la misma carta de abril de 1926, a quien retrata como el más grato de cuantos colegas ha conocido en España, en absoluto arrogante, como Meyer-Lübke le había hecho creer y como al propio Spitzer le había parecido a través de la correspondencia. Toda la carta de 21 de abril de 1926 es

${ }^{22}$ Revue de Dialectologie Romane, 6, 1914, págs. 81-138, 237-240 (apud Catalán, op. cit., pág. 37).

${ }^{23}$ Su Studien zur hispanischen Wortdeutung, Firenze, Monnier, 1885. 
un testimonio inigualable de la opinión que la vida española, los españoles en general, y algunos colegas en particular, despiertan en él; también ahí se menciona la inviabilidad de la traducción al español del Schuchardt-Brevier; encuentra en ello algo sospechoso, lo que es comprensible, pues el propio Menéndez Pidal había prometido a Schuchardt por carta su traducción española.

Las referencias a los españoles van aumentando conforme pasa el tiempo: Navarro Tomás, García de Diego, Rodríguez Marín, Bosch-Gimpera, Griera, Julio de Urquijo... las relaciones daban sus frutos. Se recoge al final del libro un índice con breves comentarios de las personalidades citadas a lo largo de la correspondencia, que han sido convenientemente señaladas en negritas. Hay alguna laguna que tiene su explicación: en carta de 15 de octubre de 1926 dice escuetamente Spitzer: «El trabajo de Alonso es excelente» (pág. 401): a pesar de haber sido resaltado con negrita, nada se dice sobre Alonso en el índice final, pues realmente no hay ningún dato que permita identificarlo como Dámaso o como Amado. Las referencias a catalanes y vascos refuerzan la visión del arco peninsular que hay en esta correspondencia; alguna ausencia de hispanistas ilustres se explica por el menor conocimiento de este ámbito por el editor del libro ${ }^{24}$.

Por otra parte, dada la importancia de las referencias a trabajos publicados en revistas varias, que el editor anota cuidadosamente a pie de página en los lugares correspondientes, hubiera sido muy deseable completar estas referencias con un índice final, al igual que se ha hecho con las personalidades de relieve. Los libros mencionados en la correspondencia pueden ser buscados a través de sus autores, que sí están recopilados en el índice final, pero no así las revistas. Un índice de revistas sería, además, una forma de mostrar en cuán gran medida han ejercido un papel de primer orden en la investigación filológica del mundo románico y europeo.

Tanto las fotografías del maduro Spitzer tomadas en 1952 en Baltimore, la de su boda en 1919, o la del joven profesor en la Universidad de Marburg en 1925 que acompañan el libro, como las varias de Hugo Schuchardt en su Villa Malwine de Graz en la época de su intercambio epistolar, además de otras ilustraciones y algún fragmento espléndidamente fotografiado de la correspondencia entre ambos (todo ello cuidadosamente seleccionado por el editor de la obra, Bernhard Hurch) contribuyen a situar la actividad filológica en su justa dimensión humana, a la par que constituyen un modelo del buen hacer que caracteriza a la obra impresa en tierra germánica.

${ }^{24}$ Spitzer fue uno de los primeros estudiosos en advertir la importancia de la edición de las Soledades de Góngora hecha por Dámaso Alonso, obra a la que dedicó su trabajo «Zu Góngoras Soledades», Volkstum und Kultur der Romanen, 3, 1930, págs. 244-258 (luego en Romanische Stil- und Literaturstudien, Marburg, 2, 1931, págs. 126-140). 
Toda la época dorada del hispanismo de los años veinte aflora en este libro cuidadosamente impreso y excelentemente planificado. Su lectura nos devuelve a un pasado que ya no regresará, pero sigue siendo sólido cimiento de la Filología hispánica. Ahora, con el progreso habido en el conocimiento y métodos de las nuevas corrientes, y tras la recuperación académica y científica de las diversas Filologías peninsulares, sería ya posible el cultivo de una Filología hispánica en su más pleno sentido al estilo de la ofrecida en este espléndido libro. 